\title{
NEW HERMITE-HADAMARD INEQUALITIES VIA FRACTIONAL INTEGRALS, WHOSE ABSOLUTE VALUES OF SECOND DERIVATIVES IS P-CONVEX
}

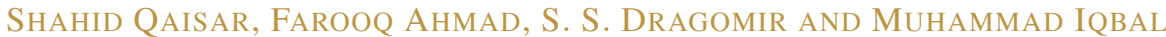

Abstract. In this research article, authors have established a general integral identity for RiemannLiouville fractional integrals. Some new results related to the left-hand side of Hermite-Hadamard type integral inequalities utilizing this integral identity for the class of functions whose second derivatives at some power are P-convex are obtained.The presented results have some closely connection with [M. E. Özdemir, C. Yıldız, A. O. Akdemir, E. Set, On some inequalities for s-convex functions and applications, Jounal of Inequalities and Applications, 2013:333]

Mathematics subject classification (2010): 26A15, 26A51, 26D10.

Keywords and phrases: Hermite-Hadamard type inequality, convex functions, power-mean inequality, Riemann-Liouville fractional integral.

\section{REFERENCES}

[1] S. S. Dragomir And C. E. M. PeArCe, Selected topics on Hermite-Hadamard inequalities and applications, RGMIA Monographs, Victoria University, 2000, online: http://www.sta.vu . edu . au/ RGMIA/monographs/hermite_hadamard.html.

[2] G. Anastassiou, M. R. Hooshmandasl, A. Ghasemi, F. Moftakharzadeh, Montogomery identities for fractional integrals and related fractional inequalities, J. Ineq. Pure Appl. Math. 10 (4) (2009) Art. 97.

[3] S. Belarbi, Z. Dahmani, On some new fractional integral inequalities, J. Ineq. Pure Appl. Math. 10 (3) (2009) Art. 86.

[4] Z. Dahmani, New inequalities in fractional integrals, International Journal of Nonlinear Science 9 (4) (2010), 493-497.

[5] Z. Dahmani, On Minkowski and Hermite-Hadamard integral inequalities via fractional integration, Ann. Funct. Anal. 1 (1) (2010), 51-58.

[6] Z. Dahmani, L. TABharit, S. TAF, New generalizations of Grüss inequality using RiemannLiouville fractional integrals, Bull. Math. Anal. Appl. 2 (3) (2010), 93-99.

[7] Z. Dahmani, L. Tabharit, S. TAF, Some fractional integral inequalities, Nonl. Sci. Lett. A, 1 (2) (2010), 155-160.

[8] S. S. Dragomir, M. I. Bhatti, M. IQbal, and M. Muddassar, Some new fractional Integral Hermite-Hadamard type inequalities, Journal of Computational Analysis and Application 18 (4) (2015), 655-661.

[9] M. Iqbal, S. QAisar, M. Muddassar, A short note on integral inequality of type HermiteHadamard through convexity, Journal of computational analysis and application 21 (5) (2016), 946953.

[10] M. I. Bahtti, M. IQbal, S. S. Dragomir, Some new fractional integral inequalities HermiteHadamard type inequalities, Journal of computational analysis and application 16 (4) (2015), 643653.

[11] M. E. ÖZdemir, C. Yildiz, A. O. Akdemir, E. SET, On some inequalities for s-convex functions and applications, J. Ineq. \& Appl. (2013) (333). 
[12] S. QAis AR, M. IQBaL, M. Muddassar, New Hermite-Hadamard's inequalities for preinvex function via fractional integrals, Journal of computational analysis and application 20 (7) (2016), 1318 1328.

[13] M. Z. Sarikaya, E. Set, H. Yaldiz And N. Basak, Hermite-Hadamard's inequalities for fractional integrals and related fractional inequalities, Mathematical and Computer Modelling 57 (9-10), 2403-2407, (2013).

[14] M. Z. SARIKAYA, N. AKTAN, On the generalization of some integral inequalities and their applications, Mathematical and computer Modelling 54 (9) (2011), 2175-2182.

[15] C. FeIXIANG, Extension of the Hermite-Hadamard inequality for convex function via fractional integrals, Journal of Mathematical Inequalities 10 (1) (2016), 75-81. 